Article

\title{
An Exploratory Study of the Sustainable Practices Used at Each Level of the Bordeaux Wine Value Chain
}

\author{
Caroline Tahon ${ }^{1, *}$ and Peter J. Batt ${ }^{1,2, *}$ \\ 1 IESEG School of Management, La Defense, 92044 Paris, France \\ 2 Institute of Agriculture, University of Western Australia, Perth 6009, Australia \\ * Correspondence: caroline.tahon@ieseg.fr (C.T.); p.batt@ieseg.fr (P.J.B.)
}

Citation: Tahon, C.; Batt, P.J. An Exploratory Study of the Sustainable Practices Used at Each Level of the Bordeaux Wine Value Chain. Sustainability 2021, 13, 9760 . https://doi.org/10.3390/su13179760

Academic Editors: Maria Pilar Martinez-Ruiz and Alicia Izquierdo-Yusta

Received: 15 June 2021

Accepted: 25 August 2021

Published: 30 August 2021

Publisher's Note: MDPI stays neutral with regard to jurisdictional claims in published maps and institutional affiliations.

Copyright: (C) 2021 by the authors Licensee MDPI, Basel, Switzerland. This article is an open access article distributed under the terms and conditions of the Creative Commons Attribution (CC BY) license (https:/ / creativecommons.org/licenses/by/ $4.0 /)$.

\begin{abstract}
This paper explores environmental and socially sustainable practices among different actors in the Bordeaux wine value chain (WVC). The main research question is to identify the extent to which the different actors in the wine value chain are aligned in terms of practices and beliefs concerning the importance and implementation of sustainable practices. While each actor in the Bordeaux WVC performs different sustainable practices depending on the activities that they undertake, some share common practices and exert some upstream pressure on the value chain as they seek to support sustainable practices at the wine grape grower and wine producer level. Environmentally sustainable practices are more developed than socially sustainable practices and were more widely adopted by most of the WVC actors.
\end{abstract}

Keywords: wine value chain; Bordeaux; sustainability; sustainable practices

\section{Introduction}

For agriculture to be more sustainable, which is one of the main goals of the 2030 Agenda for Sustainability Development [1], encouraging the adoption of more sustainable approaches and technologies is fundamental. In the current resource-intensive system within which agriculture is operating, it will be necessary to foster new approaches which enhance all three aspects of sustainability: economic, environmental and social. This approach, often called the 3Ps, insists on the complementarity of profit, planet and people [2].

In recent years, with an increased awareness of environmental issues and in response to growing stakeholder pressure, the adoption of more sustainable practices in the wine industry has become more widespread [3,4].

In 2016, in response to the various demands facing the wine industry, the International Organization of Vine and Wine (OIV) defined sustainable vitiviniculture as a "global strategy on the scale of grape production and processing systems, incorporating at the same time the economic sustainability of structures and territories, producing quality products, considering requirements of precision in sustainable viticulture, risks to the environment, product safety and consumer health, and valuing of heritage, historical, cultural, ecological and landscape aspects" [5]. In part, this definition provides guidelines for environmental assessment in terms of production, processing and packaging.

In moving towards the development of an environmental management system for the Californian wine industry, Silverman, Marshall and Cordano (2005) developed a framework based on three integrated business activities: (i) the vineyard; (ii) the winery; and (iii) distribution and consumption [6]. The environmental impacts associated with growing wine grapes are agricultural in nature, while those in the winery are generally related to food processing. Vineyard inputs include the various capital costs associated with land preparation, infrastructure (trellising, irrigation and machinery) and the ongoing operational costs associated with the application of fertilizers, pesticides, herbicides and fungicides, water for irrigation and energy to power equipment in the field. Winery inputs similarly include the capital costs of infrastructure (buildings, vats, equipment and 
machinery) and the ongoing costs of energy, water, chemicals, oak barrels and packaging materials (including glass, corks, wooden pallets, glues, cardboard, metal and plastic foil). While distribution and consumption occurs beyond the farm gate and is thus, to some extent, beyond the control of the wineries, the key issues here relate to the consumption of energy (in transport and storage), and the environmental costs associated with the disposal of packaging including cardboard cartons and bottles.

While much attention has been directed towards the adoption of improved environmental management practices in the vineyard [7-14], the environmental impacts arising from the downstream processing of grapes, the packaging of wine, and the subsequent distribution and marketing of wine may be much greater [4]. Hence, for the whole WVC to be sustainable, there needs to be a certain alignment between the different actors in terms of economic, environmental and socially sustainable practices.

Using a combination of tools (value chain analysis and life cycle analysis), Soosay, Fearne and Dent (2012) identified the various activities that were performed at each stage of the WVC and the contribution those activities made to greenhouse gas emissions [15]. Ponstein, Ghinoi and Steiner (2019) similarly used life cycle analysis to investigate greenhouse gas emissions for imported wines into Finland [16]. More recently, Baiano (2021) provides a comprehensive review of the literature describing the indicators of sustainability at the vineyard, winery and supply chain level [17]. While various activities are identified at each stage of the value chain and their impact noted, sustainable practices are particularly detailed and numerous at the wine grape growing and wine production levels, but much less information is provided for distributors, retailers and institutional users. Moreover, environmentally sustainable practices are considerably more developed than socially sustainable practices.

France has approximately 95,000 wineries and 1500 wine wholesalers and cooperatives [18]. With 383 wine appellations, 307 of which are AOC-AOP and 76 Protected Geographical Indications [5], France is recognized as one of the traditional Old World wine producers. According to the OIV (2019), France is the world's second largest wine producer (49.1 million hectalitres) and the world's second largest consumer of wine (28.6 million hectalitres) [19]. With exports of approximately 14.9 million hectalitres, France is the world's third largest exporter, but by value, with wine sales exceeding Euro 9083 million, France is the world's largest wine exporter.

This study focuses on the region of Bordeaux, which collectively includes 5800 wine grape growers and over 114,000 hectares of vines [20]. The region of Bordeaux was selected for this study as sustainable practices and more precisely the SME (Système de Management Environmental du vin de Bordeaux) have been operating since 2010. By $2019,65 \%$ of Bordeaux vineyards had been accredited under one or more environmental management certificates [20]. This study provides an extensive qualitative analysis of the different sustainable practices employed by different actors in the Bordeaux WVC and seeks to determine the extent to which the different actors in the wine value chain are aligned in terms of practices and beliefs concerning the importance and implementation of sustainable vitiviniculture practices.

\section{Literature Review}

\subsection{Sustainability}

Sustainability is most often conceptualized as being comprised of three main pillars: economic, social and environmental. As presented by Elkington (1999), businesses today must focus on the Triple Bottom Line which considers social justice, economic prosperity and environmental quality [21]. Shnayder et al. (2015) presented the Triple Bottom Line Framework and introduced the complementarity between people, planet and profit (3Ps) [2]. The challenge is for business to generate sufficient income to facilitate investment, while simultaneously caring for the environment, for the people and their communities. However, all three dimensions must be considered together, as strategic decisions taken for one element will impact on the other two [22]. 
Being sustainable is more important now than ever before as food businesses must meet the needs of an increasing population and dietary changes, without diminishing natural resources and adapting to climate change [1]. With pressures from stakeholders and society, sustainability has now become a must-have for businesses, including the European wine industry [23].

\subsection{Wine Value Chain}

According to the FAO (2017), value chains are "composed of the full range of farms and enterprises and their value-adding activities, which produce agricultural raw materials and transform them into food products that are sold to final consumers and disposed of after use" (p. 37) [1].

The value chain for this study is the wine value chain (WVC). The WVC has been studied as a specific branch of the food value chain and is often compared to food value chains when looking into sustainability [24]. Goncharuk et al. (2017) defined the WVC as "a network of stakeholders involved in growing, processing and selling the wine that consumers drink" (p. 2) [25].

WVCs have been segmented by Meissenheimer et al. (2001) [26] into activities that include

- Soils and plant material,

- Vineyard practices,

- Cellar practices and wine making,

- Packaging and distribution, and

- Market development and marketing.

WVC face global and environmental challenges, methodological and financial challenges, and challenges linked to the economy and the market [25]. Global and environmental challenges include climate change and environmental damage, due to inputs and outputs directly used and generated by the WVC. Methodological challenges are linked to the fact that value chains have been traditionally studied from an economic perspective without considering issues linked to sustainability. However, firms may miss opportunities to secure competitive advantages that may be derived from social and environmental sustainability. Financial challenges are linked to financing, high initial investment, high taxes and poor government funding. The economic and market challenges are explained by the fact that all firms now operate in a highly competitive global market environment. With the emergence of New World wine producers, the wine industry has become increasingly globalized and internationalized [27].

According to Goncharuk et al. (2017) [25], the wine value chain (WVC) involves many different actors (Figure 1). Wine grape growers are responsible for growing high-quality wine grapes for wine production. Wine producers (wineries) subsequently transform the wine grapes into wine through such activities as de-stemming, crushing, fermenting and storing. This actor also implements operations linked to packaging, thus they are in contact with suppliers providing them with bottles, corks, capsules, labels, boxes and pallets. Distributors take care of all transport-related activities. While large wine companies can control the full WVC and sell their own product, smaller wineries generally work with specialized distributors such as merchants, traders and wholesalers, importers and exporters. Retail is a major actor in the WVC as it includes institutional users (hotels and restaurants), specialty wine shops, supermarkets and convenience stores. 


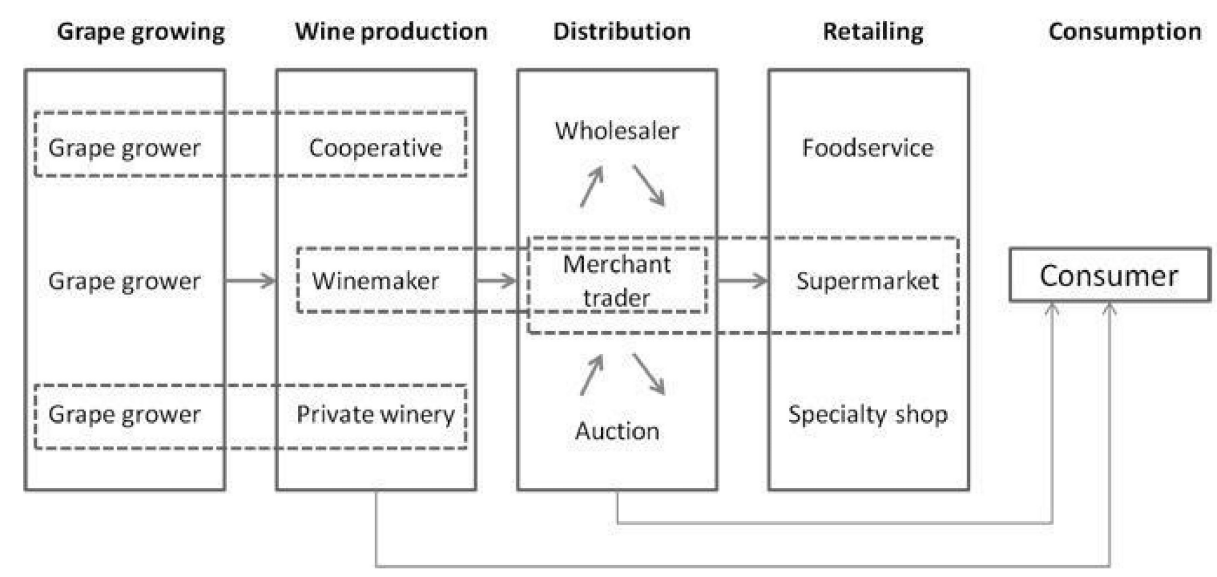

Figure 1. A framework for the wine value chain (Goncharuk et al. 2017) [4].

\subsection{Sustainable Practices}

According to the FAO (2017) [1], one of the objectives of sustainable agriculture is to reduce the dependence on fossil fuels and to reduce levels of greenhouse gas emissions. The focus is on reducing energy, fuel and water consumption, and the use of chemical products such as fertilizers, insecticides and herbicides. Renewable energy such as solar and biogas should be considered as an alternative source of energy for cooling, electricity and transport [28]. However, one of the main motivations for wine grape growers is to improve the land for generations to come [13].

The literature has identified various environmental and socially sustainable practices in the WVC. Silverman et al. (2005) [6] identified environmentally sustainable vineyard and winery practices linked to the reduction in polluting inputs (pesticides, fungicides and herbicides), water use, soil erosion and waste management.

Environmentally sustainable practices in wine production are mainly linked to soil management, water management, wastewater management, biodiversity, solid waste, energy use, air quality, and agrochemical use [28].

Five aspects have been studied in the WVC to differentiate local from global: (i) the geographic distance between consumption and production; (ii) the number of intermediaries involved in the value chain; (iii) the inputs; (iv) the governance level; and (v) the product identity built along the chain. Brunori et al. (2016) reports that most French wineries have adopted practices for landscape and biodiversity management, and show an interest in local circular economies, recycling effluents and waste, as well as optimizing water use and the reuse of domestic grey water [29].

Different practices have been identified when looking at environmental sustainability as a source of competitive advantage [30] or as a tool to increase competitiveness [31]. A Code Workbook developed by the California Winegrowing Alliance includes 138 vineyard practices and 103 winery practices [32]. The first chapter of the Workbook concerns integrating sustainability into the strategy of the business (in the mission statement and vision) and implementing an Environmental Compliance Plan.

In the field, fertigation is only used if necessary, depending on soil and vine nutrient status; frequent soil analyses are performed to control $\mathrm{pH}$ and organic matter; appropriate equipment is used to minimize soil compaction; and an effective Integrated Pest Management (IPM) program developed to manage pests with optimal levels of biological, cultural and chemical tools to minimize the negative economic, health and environmental impacts. An energy audit is conducted to measure irrigation pumps, equipment, refrigeration and lighting; vineyard vehicles may use alternative fuel such as biodiesel, propane or methane and the amount of fuel is known and tracked in the vineyard. The refrigeration system is optimized by insulation, night air cooling or off-peak evaporative cooling and renewable energy is utilized (wind, solar photovoltaic, passive solar thermal, methane digesters, biodiesel, geothermal, or green power of any type). Hazardous wastes are monitored and 
stored appropriately to be recycled when possible. Oak barrels are bar-coded and ideally made from sustainably harvested wood and recycled, all glass is separated and recycled, cardboard is reduced or reused or recycled, corks have an alternative disposal mode (recycling or composting), an Environmentally Preferable Purchasing policy is established, and the amount of packaging used by suppliers is taken into consideration in purchasing decisions [32].

However, for the WVC to be sustainable, it is important for the distribution and retail channels to minimize transport costs and carbon emissions [30]. Concerning transportation, the Code Workbook (2012) [32] suggests acknowledging the links between miles traveled and air quality, and to minimize the distance wherever possible.

The concept of the three Rs (reduce, reuse and recycle) is applied wherever possible. This applies particularly to recyclable packaging material; packaging is reduced, reused and recycled; and pallets are repaired or reused when possible [32].

Examples of sustainable practices at the retail level include the separation and collection of packaging. This can be achieved by talking with vendors who can take back pallets, bins and other packaging for reuse [32]. Flint and Golicic (2009) [30] conclude that to be truly sustainable, actors in the WVC should work with local supply businesses sharing the same values in order to be aligned with a common environmental focus.

In considering socially sustainable practices in the wine industry, Thach (2002) [33] identified practices linked to occupational health and safety and development training, pay system bonuses and other incentives for seasonal workers such as housing or health insurance. These practices have been identified in the US and defined as Human Resource (HR) sustainability. Thirty-three HR best practices have been identified, including training linked to occupational health and safety, safe job performance, but also language training and training to learn the business of wine. Other best practices are linked to salary and include workers compensation, bonuses and perks for employees.

Barbosa et al. (2018) [31] recommended establishing a close relationship between wine businesses and the local community to promote and encourage awareness concerning sustainable practices, as well as environmental education, and to provide employees with a health plan and study grants.

Forbes et al. (2020) [3] identified the people involved in the wine industry as employees, the local community, wider society, consumers and other stakeholders. This study presents different cases through CSR initiatives, biodynamic certifications, stakeholder involvement, charity, social enterprise and philanthropy. It presents various voluntary initiatives taken in the wine industry that enabled wineries to differentiate their offer or at least to have a positive impact on the social sustainability of their businesses.

The Code Workbook (2012) [32] specifies that HR planning should be undertaken with the objective of having a long-term staffing strategy including staffing and recruitment, training and development, employee relations, compensation and benefits, as well as HR goals such as employee retention. Safety training as well as any type of continuous training are to be encouraged to develop new skills within the industry. Sustainability should be promoted among all employees to facilitate successful adoption and implementation of sustainable practices.

Socially sustainable practices concerning neighbors and communities include communicating with them regularly and acting upon their comments, questions and concerns; meeting with relevant stakeholders to address issues and proactively working to minimize potential negative impacts [32].

\subsection{Sustainability Frameworks}

Assessing sustainability can be performed at each level of the value chain through general frameworks such as the ISO standards or the GRI sustainability reports. The ISO 14001 Environmental Management System is used in many regions. However, another and more widely used option is for wine regions to create their own frameworks [34]. 
The main issue with these regional frameworks is that they do not allow consumers to have a common basis to compare sustainable practices across different wine regions [34]. Furthermore, these frameworks often do not take into consideration the dynamic nature of sustainability in performance evaluation [35].

The first sustainable winegrowing program was created in 1992 by the Lodi Winegrape Commission (LWC) from California. The first Lodi Winegrower's Workbook was published in 1997. The LWC now provides self-assessment programs and workbooks that have led to the increased adoption of sustainable practices in this region [28]. The LWC also created a third-party certification program for sustainable wine grape growing.

Since then, many other institutions and organizations have developed their own guidelines for sustainable wine grape growing. In France, at least three of them have been studied in the literature: the environmental management system developed by the Bordeaux Wine Council (OIV), the Terra Vitis environmental certification recognized by the Ministry of Agriculture [34] and the Vignerons en Développement Durable (VDD) CSR label [11].

Some international frameworks have also been used to measure sustainability in the wine industry such as the Food Alliance Criteria for social sustainability and the Low Input Viticulture and Enology organization (LIVE) sustainable practices for environmental sustainability [24].

\section{Methodology}

\subsection{Research Procedure}

A qualitative approach was adopted for this study as it enabled the researcher to dig deeply into the different actors' views and practices towards sustainability. This study used semi-structured interviews to explore and discover unexpected concepts and ideas. According to Moscarola (2015) [36], interviews should be conducted with knowledgeable individuals who speak about a specific topic in order to collect information.

By conducting qualitative semi-structured interviews, data were collected at each stage of the value chain. Walking the chain allowed the researcher to understand the nature of the relationships between the different actors and to understand the extent of alignment or differences in terms of sustainable practices.

The semi-structured interviews were based on an interview guide which was developed to extract information from each actor of the WVC. To be selected, respondents had to be a key actor in the WVC: namely wine grape growers, wine producers, distributors and retailers. Respondents were facility managers, vineyard managers, and managers in the distribution or retail of Bordeaux wines.

Purposive sampling was employed as it allowed the researcher to identify and select participants that were experienced and knowledgeable about the phenomenon under study [37]. Moreover, it was important to consider the availability and willingness of selected individuals to participate in this study.

The region of Bordeaux was selected for this study as sustainable practices and more precisely the SME (Système de Management Environnemental du vin de Bordeaux) have been operating since 2010. By 2019,65\% of Bordeaux vineyards had been accredited under one or more environmental management certificates [20].

Selected individuals were first contacted by email or through professional networks to pre-arrange the interviews. A variety of both small and large, new and old businesses were contacted to maximize validity. However, some interviews were less formal and not pre-arranged. Extensive notes were taken during the interviews, and where possible and with the permission of the respondent, recorded.

The research framework used for this study is presented below (Figure 2): 


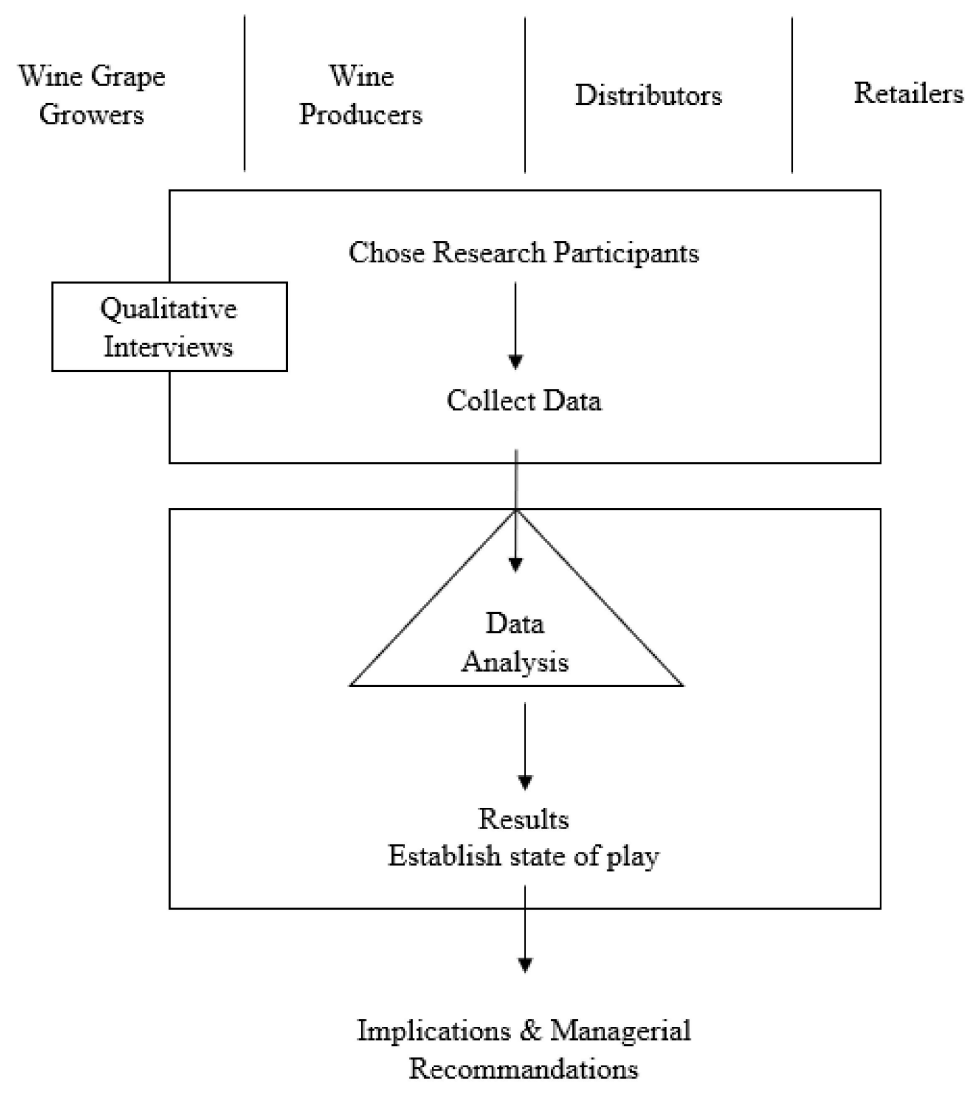

Figure 2. Research Framework.

\subsection{Data Collection}

The data were collected through face-to-face and phone interviews. These in-depth qualitative interviews were conducted from August to October 2020.

The interviews followed a semi-structured interview guide which was designed and developed in three versions, one for each type of actor in the WVC: wine grape growers and producers; distributors; and retailers.

Interviews were conducted in a conversational manner, allowing interviewees to share their personal views on sustainability and the different practices they had adopted. These open-ended conversations allowed the researcher to go beyond the questions presented initially in the interview guide and helped generate broader discussions.

The interviews were conducted in French, recorded as well as transcribed, and translated for the purpose of this research.

Of the 30 interviews, 26 were conducted by phone and 4 face-to-face. The high number of phone interviews was necessary because of the difficulties associated with physically meeting the interviews during an outbreak of COVID-19.

The average time for the interviews was $30 \mathrm{~min}$ : the shortest one lasted $18 \mathrm{~min}$ and the longest one lasted $75 \mathrm{~min}$.

For the purpose of this study, 11 wine grape growers and wine producers, 5 distributors and 14 retailers were interviewed.

\subsection{Data Analysis}

To analyze the data collected through the interviews, rigorous qualitative analysis methods were applied. Content analysis as well as lexicographic analysis were used to analyze the data collected. The interviews were supplemented by documents provided by the companies or available on their website.

Content analysis aims at obtaining a condensed and broad description of the phenomenon. This technique was particularly appropriate as it is flexible in terms of research 
design and allowed the researcher to explore meanings and contexts as well as to identify critical processes. It also helps in understanding multifaceted and sensitive phenomena [38].

According to Moscarola and Jenkins (1998) [39], there are seven levels of lexicographic analysis. Here, the "selective lexicon approach" was used, meaning that attention was concentrated on a reduced lexicon. A reduced lexicon meant that the analysis was conducted after eliminating words without a useful meaning, prepositions and articles.

The data were first analyzed separately for each actor of the WVC: wine grape growers and wine producers, distributors, and retailers. It was then analyzed from a global value chain perspective to draw conclusions concerning the alignment and differences in terms of practices.

\section{Results}

\subsection{Descriptive Statistics}

\subsubsection{Wine Grape Growers and Wine Producers}

Wine grape growers and wine producers were analyzed as one actor. In the region of Bordeaux, wine grape growers are almost always wine producers as they make their wine in their own winery with the grapes harvested from their vineyard(s).

For this actor in the wine value chain, 11 individuals were interviewed. Among the interviewees, two were women (18\%) and the remaining $82 \%$ were male participants.

Their experience in the wine industry ranged from 3 to 25 years, with an average of 14 years.

The positions of the interviewees differed from Managing Director to HSEQ (Health, Safety, Environment, Quality), CSR (Corporate and Social Responsibility) manager, Maître de Chai or external vine consultant.

\subsubsection{Distributors}

Concerning the distributors, five individuals working in this sector were interviewed. Among the interviewees, one was a woman and the remaining four were male respondents.

They all had significant experience in the wine industry, with an average of 13.4 years, with 2.7 years in their current position.

One respondent $(20 \%)$ was an individual entrepreneur working as a self-employed négociant, while the other four interviewees worked for well-established wine distributors. In the Bordeaux region, wine is mainly sold through companies functioning as distributors called négociants. The size of their business and the number of employees was highly variable.

\subsubsection{Retailers}

For this actor in the WVC, 14 individuals were interviewed. They were studied separately following Goncharuk et al. (2017) WVC framework: food service (grouping hotels and restaurants); supermarkets and specialty wine shops [25]. Moreover, one B2B and one B2C online retailer were interviewed.

The following actors of the retail sector were interviewed: 2 supermarkets, 3 specialty wine shops, and 8 actors from the food service sector-2 hotels, 1 catering institution, 5 restaurants and finally 1 online $\mathrm{B} 2 \mathrm{C}$ and 1 online $\mathrm{B} 2 \mathrm{~B}$ retailer.

Among these interviewees, three were women (21\%), with the remaining $79 \%$ being male participants. Their experience in their current position ranged from 1 year to 30 years, with an average of 8 years.

The positions of the interviewees differed from owner and manager to category manager or sommelier, depending on the retailer's specific activity. 


\subsection{Findings}

\subsubsection{Wine Grapes Growers and Wine Producers}

Environmentally sustainable practices have been identified both in the vineyard and in the winery and thus these will be presented separately. Concerning socially sustainable practices no distinction was made.

Environmentally Sustainable Practices

Vineyard Level

Soil Management

- Soil protection and improvement

The soil was mentioned often as being a key element in making good wine. The first element seemed to involve the knowledge of the soil, by evaluating, testing and analyzing the soil. This practice was mentioned by $18 \%$ of interviewees.

For the soil to be living and rich in terms of microbial life, many different practices were mentioned, all linked with the creation of organic matter. Covering soils (mulching) seemed to be a preferred option for many wine grape growers. However, controlling weeds either chemically (with herbicides), or mechanically was a very common practice. Mechanical means of weed control was the preferred option by $40 \%$ of the respondents as it helped to reduce the use of chemicals. However, mechanical work performed with the assistance of tractors could lead to soil compaction. Two alternatives were mentioned: horse traction in the vineyard and hydroseeding.

- Reduction in phytosanitary products

The biggest challenge for wine grape growers was reducing the use of phytosanitary products. Reducing phytosanitary products could be achieved through the use of decisionmaking tools such as a meteorological station. It also included calculating the use of phytosanitary products through IFT. Moreover, some specific tools and innovations were mentioned as a way to reduce the use of phytosanitary products such as electronic mapping, anti-drift nozzles and investments in research and development.

- Collection (and treatment) of effluents

Regulatory pressures were one of the drivers motivating the collection of effluent.

- Alternatives to phytosanitary products

Copper and sulfur were used in organic viticulture as well as natural fertilizers. Biological control was also widely used, with some $20 \%$ of respondents using mating disruption as a means of controlling insect pests.

Biodiversity

Enhancing and encouraging biodiversity was a priority for wine grape growers. This was mainly achieved through the allotment of green spaces, hedges, forests and trees. Agroforestry and agroecology were mentioned by $18 \%$ of the respondents, both as a way to create organic matter and as good practices in terms of enhancing biodiversity.

Water Management

The first element in conserving water was to identify water consumption. Waste water management involved collecting rainwater as well as runoff water. In a few instances $(10 \%)$, drainage systems were also mentioned.

$\mathrm{CO}_{2}$ Emissions

$\mathrm{CO}_{2}$ emissions were determined by calculating the carbon footprint. At the vineyard level, $\mathrm{CO}_{2}$ emissions were primarily linked to the use of tractors in cultivating the soil, the application of chemicals and fertilizers, and in transporting grapes to the winery.

Winery Level

Energy and Water Consumption 
The two most heavily used resources in the winery were electricity and water. Wine makers mentioned different practices to conserve or reduce the use of both.

- $\quad$ Electricity Consumption

Lighting within the winery was the first most obvious consumer of electricity. However, for wine makers, the biggest use of electricity was linked to the cooling of the wine during fermentation. One way of limiting energy consumption was natural fermentation. Renewable energy was mentioned by only one respondent.

\section{- Water Consumption}

Water was mainly used in the cooling process and for cleaning in the winery. Concerning the cooling process, $18 \%$ of the respondents mentioned working with water in a closed circuit with a heat pump or thermoregulator. Only one wine maker said he did not use water for the cooling process. Concerning cleaning, one wine maker noted that it was not possible to reduce water consumption. However, sustainable water management practices included the use of recycled water and having a treatment plant for wastewater (40\% of respondents).

Use of Inputs

In the oenological and winemaking process, some external inputs were used. However, wine makers were rather vague concerning the inputs they specifically used in the winemaking process and their impact on sustainable practices. Some $18 \%$ of respondents mentioned that they were using less sulfur dioxide (as a preservative). One respondent $(10 \%)$ insisted on the use of indigenous yeast.

Waste Management

There were clear regulatory guidelines about the treatment of waste in the winery.

Packaging and Dry Materials

Making wine involves using many different dry materials such as bottles, corks, labels, capsules, cardboard and pallets.

Most wine makers had not undertaken any sustainable actions concerning the purchase of dry materials. However, some $18 \%$ of respondents were conscious of the sustainable issues associated with dry materials. To operate more sustainably in terms of dry material, the first step was to engage with suppliers. More specifically, this meant using lighter bottles and/or bottles made from recycled glass. For corks, traceability was important. Concerning labels, interviewees took into account the adhesive, the material (paper rather than plastic) and the ink (water-based preferred). Capsules could be used to replace beeswax for example. Cardboard could be recycled. However, almost all wine makers were involved with the recycling of pallets.

Environmental Management Systems

At the wine grape growing and winery levels, $80 \%$ of the respondents worked under an EMS with $73 \%$ of interviewees certified or in the process of obtaining certification. Among the interviewees, 45\% had HVE3 (High Environmental Value) certification.

The second most widely used certification was the organic viticulture certification, with $30 \%$ of the respondents being organically certified. On top of being HVE3 certified, one respondent also mentioned ISO14001 (the international recognized standard for environmental management) and ISO26001 (the internationally recognized standard for CSR).

Value Chain Level

Some $27 \%$ of respondents mentioned the importance of short value chains by encouraging short, local and direct marketing options.

\section{Socially Sustainable Practices}

When looking at socially sustainable practices, wine grape growers and wine makers could be divided into one of two categories: those that did not mention any socially sustainable practices $(40 \%)$, and those actors that did (60\%). Among those that recognized the importance of socially sustainable business practice, identifying stakeholders was the 
starting point. Among the identified practices, they either benefited employees or the local community.

Benefitting Employees

- Health and safety

The health and safety of employees was the priority for most wineries. Practices involved sensitizing employees and having appropriate machines and equipment.

- Well-being and working conditions

Offering good working conditions to employees was the second most important aspect. This meant providing them with dedicated space and perks, comfortable and suitable working tools.

- $\quad$ Training

Some $30 \%$ of the respondents mentioned the importance of training employees.

- Reward and remuneration aspects

Remuneration and bonuses were mentioned by $30 \%$ of respondents.

- Empowering employees

The importance of sharing a common vision and transforming employees into actors of change was mentioned by $18 \%$ of respondents. This could be achieved through change management processes or workshops. However, to empower employees, management and leadership were identified as important preconditions by one respondent.

- $\quad$ Recruiting

Some $40 \%$ of the respondents noted that while there was a high level of unemployment in the region of Bordeaux, it was also very challenging to recruit qualified employees. Two solutions were mentioned by the respondents: hiring locally through the collective training of young professionals or creating a private-public-partnership with a state agency or NGO.

Benefiting the Local Community

The second major stakeholder was the local community and more specifically neighbors. The first step was to identify and understand their concerns. To rectify the situation, the first suggestion was to use common sense. However, there were numerous legal obligations framing the relationship between wine makers and their local community. The best practice to understand and reassure the local community was communication. This could be achieved by creating links with them or via SMS. One respondent spoke of the need for community promotion campaigns.

However, in the current environment where many wineries were struggling financially, without being profitable, it was very challenging for many wineries to make the necessary investments to comply with sustainable practices.

\subsubsection{Distributors}

Environmentally Sustainable Practices

Concerning sustainable environmental practices, various elements and practices were mentioned and identified by distributors:

$\mathrm{CO}_{2}$ emissions

$\mathrm{CO}_{2}$ emissions were mentioned by all of the interviewed distributors. It was for them an essential issue to work on. At this level of the WVC, various practices could be put in place at various activity levels: transportation; the vineyard and winery; and at the office level.

- Transportation

Regarding $\mathrm{CO}_{2}$ emissions, all respondents mentioned transport as a key issue at least once in their response. Some of the suggestions made to reduce the environmental impact of transportation included encouraging shorter value chains, grouping orders, and optimizing transportation. 
- Vineyard and winery level

While reducing $\mathrm{CO}_{2}$ emissions should be achieved at all levels of the WVC, distributors felt that they had a responsibility towards other actors in the WVC. One of the distributors had created an environmental charter to help producers to switch to more sustainable viticulture. The charter proposed 10 alternatives to conventional techniques and took into account the barriers the winemaker may face. This distributor also presented itself as a partner for winemakers and offered to help in this transition process through a 5-step methodology: informing, auditing, improving, convincing and communicating.

This idea of working at the vine and winery level was shared by $40 \%$ of the distributors. One distributor shared his individual knowledge with wine suppliers by creating a strong and close relationship where transparency was key. For those owning their own bottling lines or wine store house, reducing their environmental impact meant investing in upto-date equipment and being certified. Working at the vine and wine level also meant selecting their wine providers carefully, with $40 \%$ of distributors mentioning the importance of selecting their partners.

Office Level

Looking at the office level, the practices put in place seem obvious but were just as important. Such measures were easy to follow up and to measure. Moreover, the practices seemed to involve the actors at an individual level. Concerning $\mathrm{CO}_{2}$ emissions at the office level, one of the practices identified included the use of a shared vehicle. However, most of the practices mentioned at the office level concerned waste management.

- $\quad$ Reducing and recycling wastes

It was very easy for interviewees to come up with well-established practices in the office. For $80 \%$ of them, reducing paper consumption and paper recycling had the biggest impact. However, paper was not the only issue to focus on as distributors could also take actions on single-use plastic and cardboard.

- Packaging

Some distributors buy finished goods, meaning bottles of wine in cartons of 6, ready to be sold. Others bought wine in bulk and were responsible for bottling it. In the wine industry, when talking about packaging, it often meant dry materials namely: bottles, labels, corks, capsules, cardboard or wooden boxes, and pallets. One distributor presented a clear strategy with concrete practices grouped under a label for all dry materials involved in the bottling process.

Water Consumption

Water consumption was mentioned only once as an issue.

Limits to Sustainable Environmental Practices:

Some limits to the deployment of more sustainable practices were mentioned by distributors. The lack of a suitable alternative was often a blocking element. The economic aspect also intervened in the decision-making process and debates about adopting more sustainable practices.

\section{Socially Sustainable Practices}

Identifying socially sustainable practices at the distributor level was more challenging than identifying environmental practices. In the mind of distributors, socially sustainable practices seemed to be linked to environmentally sustainable practices. Concerning benefits for employees, $20 \%$ of distributors presented concrete practices. Only one distributor actually provided an extensive answer about socially sustainable practices. This distributor mentioned the importance of consumers, employees and the community.

Limits to Sustainable Social Practices:

Two interviewees insisted on the fact that stakeholders should be empowered as individuals to take action. 


\subsubsection{Retailers}

Here, the results are presented separately for the foodservice sector, specialty shops, supermarkets and online retailers.

\section{Supermarkets}

Environmentally Sustainable Practices

The main environmental challenge for supermarkets was a reduction in $\mathrm{CO}_{2}$ and energy use

$\mathrm{CO}_{2}$ Reduction

A reduction in $\mathrm{CO}_{2}$ could be achieved at both the store and plant level. One of the main sources of $\mathrm{CO}_{2}$ emissions were linked to transport. In this respect, supermarkets supported green transport for their customers, with all respondents mentioning charging stations for electric vehicles. However, the supermarkets carbon footprint did not only impact on consumers' means of transport but also on their own transport chains. Wherever possible, supermarkets favored river or rail transport.

Energy Consumption

A common objective for supermarkets was to reduce energy consumption and energy costs. A global strategy for buildings was mentioned based on an eco-design guide. Solar panels were mentioned as an alternative source of energy.

Packaging and Waste

Reducing the use of plastic was mentioned by all respondents. However, the use of plastic does not only concern plastic bags, it includes any plastic packaging. Reducing waste was the first step in waste management. However, this was challenging for supermarkets as packaging was used at every step: for transport, for displaying products in store and in the final packaging of the actual product. Recycling was the second step. To improve recycling, one interviewee mentioned the importance of including consumers in this collective approach.

Selection of Products and Suppliers

The selection of products was highly regulated. For supermarkets, one of the sustainable practices was promoting local suppliers. Another practice was promoting ecoresponsible labels to leverage responsible consumption. All respondents mentioned $A B$ organic products. One supermarket insisted on purchasing only HVE3 certified wines. Finally, alternative agricultural models such as agroecology were also mentioned.

Biodiversity

Biodiversity was mentioned by one interviewee. Practices were implemented directly at the store level through a permaculture initiative or beehives on the roof of the store.

Energy Management System

ISO 50001, as an international energy management standard, was mentioned by all of the interviewees.

Socially Sustainable Practices

Benefitting the Local Community

Socially sustainable practices mainly included practices benefitting the local community. One clearly identified practice was to partner with local NGOs and associations to reduce food waste and fight poverty. Other partnerships had been put in place to foster diversity and inclusion. Another socially sustainable practice was to organize workshops and seminars to promote better health and nutrition.

Benefitting Employees

Concerning socially sustainable practices benefitting employees, the supermarkets scope was more limited, but all interviewees mentioned legally binding mandatory benefits. However, some practices were mentioned to improve employee's well-being. One interviewee mentioned specific practices to improve employees' comfort and security at work.

At the supermarket level, environmentally and socially sustainable practices were always limited by costs and customers' purchasing power and needs. 
Specialty Shops

Specialty shops are retail liquor stores selling different types of prepackaged alcoholic beverages. However, for the purpose of this study, the focus was on specialty shops selling wine.

Environmentally Sustainable Practices

$\mathrm{CO}_{2}$ Reduction

Reducing $\mathrm{CO}_{2}$ emissions were mainly linked with transport at this level of the WVC, with $66 \%$ of interviewees indicating that this was the responsibility of transporters. However, identifying $\mathrm{CO}_{2}$ emissions were seldom conducted, although one interviewee mentioned that they would like to implement green accounting.

Energy Consumption

Energy consumption is a key issue in the retail sector. One interviewee specifically mentioned avoiding using air conditioning and heating whenever possible, as well as working with a specific electricity provider.

Packaging and Waste

Minimizing packaging and waste were mentioned by all respondents. The first identified practice was the need to reduce the use of bags made from specific materials. Reusing the packaging in which they received their wines was mentioned by $66 \%$ of interviewees. Recycling was also mentioned by all specialty shops: for cardboard and paper, pallets and corks.

Selection of Products and Suppliers:

Supporting local producers and encouraging shorter distribution chains were mentioned by $66 \%$ of the respondents. Sustainability was given specific importance by one respondent. All interviewees mentioned selecting wines from certified wineries.

Socially Sustainable Practices

Benefitting Employees

One-third of the interviewees detailed their strategy in terms of practices benefitting employees that included legal benefits, flexibility in terms of working hours, discounts and product testing. Two-thirds of the respondents mentioned bonuses.

Economical Aspects and Limits to Sustainability

Price was mentioned by $66 \%$ of respondents as a limitation.

\section{Foodservice Sector}

Environmentally Sustainable Practices

$\mathrm{CO}_{2}$ Reduction

Once again, $\mathrm{CO}_{2}$ emissions for the foodservice sector were primarily linked to transport. One important aspect mentioned by $43 \%$ of respondents was limited storage space which led to small consignments of wine being delivered on a very frequent basis. Trucks seemed to be the most common means of delivery. Alternatives did not seem to be feasible for now.

Packaging and Waste

For $38 \%$ of respondents, sorting and recycling was not a legal obligation and thus no specific strategy was implemented. However, the remaining $62 \%$ of interviewees did sort and recycle packaging through dedicated bins, waste collection systems or at voluntary disposal points. Concerning corks, $43 \%$ of respondents mentioned collecting them for different purposes such as insulation for houses, artistic projects or giving them to a nonprofit organization which sold them to finance equipment for people with disabilities. One interviewee mentioned organic wastes which they recycled through compost or methane digestors to generate heat for electricity. Another mentioned the necessity of investing in a gas machine to increase wine preservation and avoid throwing away wine.

Selection of Products and Suppliers

Food service interviewees had many different criteria for selecting their wines and suppliers including the culinary combination, taste, aroma, seasonality, design and graphic choice of bottles and labels, origin of the products to enhance the terroir of the region and 
most importantly value for money to maintain a margin. Selecting sustainable or certified products was a secondary criterion, but $75 \%$ of respondents offered certified wines such as HVE3, biodynamic or organic.

Biodiversity

Biodiversity was mentioned by $12 \%$ of respondents.

Energy/Environmental Management System

None of the respondents were certified.

Issues Linked to Core Activity

Food service respondents had different priorities in terms of environmental practices and often wine was not one of them. Many of the environmental practices they had implemented included reprocessing cooking oil and converting it into biofuel, deletion of a paper menu, or changing showers and toilet systems to reduce water consumption. However, these were not directly linked with the purchase of wine.

Socially Sustainable Practices

In terms of socially sustainable practices, many of the interviewees had not implemented any specific practices.

Benefitting the Local Community

Socially sustainable practices benefitting the local community were identified among $25 \%$ of respondents. Through a partnership supporting inclusion and employment for people with disabilities, this led to a tax deduction. One respondent had implemented several different practices, first in terms of international solidarity and in terms of local territory.

Benefitting Employees

Some $50 \%$ of respondents mentioned providing their employees with minimum legal benefits. Some added extra-legal benefits including a bonus for productivity, housing, laundering and meals, and training.

Online Retailer

One B2B and one B2C online wine retailer were interviewed.

Environmentally Sustainable Practices

$\mathrm{CO}_{2}$ Reduction

To reduce $\mathrm{CO}_{2}$ emissions, one interviewee mentioned several different practices including their participation in trade fairs, favoring short distribution chains and an adapted last kilometer strategy using bicycle couriers.

Energy Consumption

Taking actions and implementing practices were challenging as suppliers were responsible for storage and transport.

Packaging and Waste

The only element mentioned concerning packaging and waste was the collection and reuse of pallets.

Selection of Products and Suppliers

One respondent mentioned taking into account sustainability when selecting wines and winemakers as well as supporting organic wines.

Socially Sustainable Practices

Benefitting the Local Community

One interviewee had created a non-profit organization, increasing the visibility of her selected wine growers and allowing them to share best practices.

\section{Discussion and Implications}

Sustainable practices presented by wine grape growers and wineries were numerous and mainly concerned with soil management, reducing the use of phytosanitary products, water management, biodiversity and minimizing $\mathrm{CO}_{2}$ emissions (Table 1). 
Table 1. Summary of Findings.

\begin{tabular}{|c|c|c|c|c|}
\hline & Wine Grape Growers & Wineries & Distributors & $\begin{array}{c}\text { Retailers } \\
\text { (Supermarkets, Specialty Shops, } \\
\text { Foodservice Sector, Online Retailer) }\end{array}$ \\
\hline $\begin{array}{l}\text { Environmental } \\
\text { Sustainable } \\
\text { Practices }\end{array}$ & $\begin{array}{c}\text { CO2 emissions } \\
\text { Soil management } \\
\text { (soil protection and } \\
\text { improvement) } \\
\text { Reduction in use of } \\
\text { phytosanitary products, } \\
\text { Water management and } \\
\text { collection of effluents } \\
\text { Biodiversity }\end{array}$ & $\begin{array}{c}\text { Electricity consumption } \\
\text { Water consumption } \\
\text { Use of inputs } \\
\text { Waste management } \\
\text { Packaging and dry material }\end{array}$ & $\begin{array}{c}\text { CO2 emissions } \\
\text { Transportation } \\
\text { Office level(waste } \\
\text { management, packaging) } \\
\text { Water consumption } \\
\text { Upstream pressure on WVC: } \\
\text { Vineyard and winery level }\end{array}$ & $\begin{array}{c}\text { Common to all retailers: } \\
\text { CO2 emissions } \\
\text { Energy consumption } \\
\text { Packaging and waste } \\
\text { Supermarkets and specialty } \\
\text { shops: Biodiversity } \\
\text { Upstream pressure on WVC: } \\
\text { Selection of products and suppliers }\end{array}$ \\
\hline $\begin{array}{l}\text { Social } \\
\text { Sustainable } \\
\text { Practices }\end{array}$ & $\begin{array}{r}\text { Benefittir } \\
\text { Health and safety, well-bein } \\
\text { reward and remuneratior } \\
\text { Benefitting l } \\
\text { Regulatory pres }\end{array}$ & $\begin{array}{l}\text { employees } \\
\text { nd work conditions, training, } \\
\text { mpowerment, recruitment } \\
\text { l communities } \\
\text { e, communication }\end{array}$ & & $\begin{array}{l}\text { Benefitting employees } \\
\text { Legal benefits, comfort, and } \\
\text { security, flexibility } \\
\text { Benefitting local communities } \\
\text { Diversity and inclusion, health, } \\
\text { and nutrition }\end{array}$ \\
\hline
\end{tabular}

For wine grape growers, their main challenge was to maintain yields while being more respectful towards the environment. The first objective for all vineyards was to have a living soil that allowed wine grapes to grow in the best way possible. All vignernons acknowledged the positive linkage between soil quality and the quality of the resultant wines. Various techniques were employed to create a living soil including the addition of organic matter or humus, minimizing compaction, regulating soil $\mathrm{pH}$ and promoting biological activity.

The second objective was to protect the vines from pests and diseases. To have healthy vines, conventional viticulture involves the use of phytosanitary chemicals, including herbicides. The most widely used alternative to phytosanitary products was to mechanically cultivate the soils, which by necessity meant using tractors that led to an increase in $\mathrm{CO}_{2}$ emissions and a disruption to soil biology and the vines root systems.

While many wine grape growers still used phytosanitary products, different practices were employed to make their application more sustainable including the use of on-farm meteorological stations, a treatment frequency index (IFT), anti-drift nozzles, variable rate application technologies, integrated pest control and methodologies to collect, treat and reprocess residual chemicals derived from the cleaning of equipment.

Preserving and protecting biodiversity was the third challenge for wine grape growers. It involved understanding the current micro-fauna, bringing together the necessary living conditions to create and support wildlife circulation. This was mainly achieved by having dedicated green spaces including hedges, forests and trees, crisscrossing the vineyards. Two practices were mentioned-agroforestry and agroecology-as a sustainable philosophy to enhance biodiversity. Trees act as regulators and present an opportunity to fight climate change. Moreover, they help fight water pollution by reducing erosion and runoff.

The fourth challenge for wine grape growers was water management. As the vines are regularly exposed to water stress, a shortage of water can negatively influence the optimal ripening of the grapes and thus the ability to produce good quality wines. However, excessive water stress can also be harmful. Due to climate change, severe drought or inadequate water supply, vines were expected to be more exposed to water stress. For now, under the Bordeaux "Appellation d'Origine Contrôlée" (AOC), irrigation is prohibited. This might change as the regulations become more flexible, but for now, irrigation was not mentioned as a vine management strategy.

The fifth challenge was to reduce $\mathrm{CO}_{2}$ emissions which were mainly linked to the use of tractors and mechanical work in the vineyard.

Concerning the winery, it was more challenging to identify concrete environmentally sustainable practices. With regard to the consumption of electricity, by implementing an LED lighting system, less energy was consumed. Moreover, solar panels could be installed 
on the winery roof. However, the most energy consuming activity was the cooling of the wine tanks. Energy consumption could be reduced by harvesting at night so that the starting temperature for maceration was lower, or the insulation of tanks and pipework.

Water was very necessary for cleaning operations in the winery. Most of the wineries in the Bordeaux region had a waste water treatment plant, with the waste water being either reused or spread on dedicated land.

In the winemaking process, many different inputs were used, some of which could be recycled. For example, grape stems, skins and seeds could be used as compost or a soil amendment and the lees could be distilled to make alcohol. Although no particular effort was made in selecting more sustainable suppliers, efforts included the use of lighter glass bottles made from recycled glass, corks derived from sustainable plantations, labels made from recycled paper and the use of water-based inks; and recycled cardboard. However, most of the current efforts were focused on the recycling of pallets for which there are norms and regulations.

At the value chain level, some interviewees mentioned the importance of shorter distribution chains. By having fewer actors involved, this could reduce their $\mathrm{CO}_{2}$ emissions, provide better control over the pricing of their wine, and create a competitive advantage by better understanding the needs of their final consumers.

Socially sustainable practices were on one hand driven by regulation and on the other hand by voluntary practices. Identified socially sustainable practices benefitted employees and/or the local community, although other stakeholders such as clients, journalists, banks and insurance companies were also mentioned.

Concerning employees, the main focus was on health and safety: practices involved protecting, sensitizing and providing employees with personal protective equipment. A secondary focus was applied to their well-being and working conditions, which involved offering employees dedicated space and accommodation, adapting tools, equipment and tractors. A third element was training, which was mandatory or directly linked with the job. Interviewees also mentioned empowering employees through change management processes and workshops.

Concerning the local community and more specifically neighbors, there were legal obligations such as a certain distance between land parcels and habitations. Voluntary practices involved identifying and understanding the local community's concerns, which could be achieved through communication and by organizing events to improve links with neighbors.

At the distribution level, the most significant impact was transportation and thus the resultant $\mathrm{CO}_{2}$ emissions. Working with specialized transporters, distributors were conscious that they had little room for negotiation. When selecting and partnering with a specialized transport company, sustainability was not an essential factor. Distributors did, however, look for certified transporters, mainly IFS and BRC certified partners, which were linked with security and quality of service.

Concrete practices and improvements that were mentioned as a solution to reduce $\mathrm{CO}_{2}$ emissions included favoring shorter distribution chains, reducing distances, and grouping orders. Rethinking transport could mean changing the whole distribution process by using electric vehicles or exploiting rail transportation.

Aside from transport activities, distributors felt they should also engage with other actors of the WVC. For a distributor, working at the winery level meant supporting wine grape growers and wine producers. This could be achieved by providing wine producers with an environmental charter to help them switch to more sustainable viticulture or by sharing individual knowledge with small wine producers.

In the selection of wine providers, sustainability was important for distributors. Distributors were interested in nonconventional agricultural practices and preferred to sell wines that respected biodynamic or organic agriculture principles. The three main labels existing in France for these differentiated ways of making wine are Demeter for 
biodynamic wines, $\mathrm{AB}$ for organic agriculture certified products and HVE3 for high environmental value.

The most obvious area where distributors felt that they could have an immediate and tangible impact on the environment was within the office. Paper consumption had been reduced through digitization and increasing awareness: paper was consumed only when it was absolutely necessary, recycled paper was used and then used again as draft paper. For one distributor, single-use plastic had been banned and replaced by acrylic plastic that could be recycled within a closed loop.

Packaging and dry materials namely bottles, labels, corks, capsules, cardboard and pallets were the key elements for which sustainable practices could be implemented. One distributor had created their own label. Sustainable practices identified at the packaging stage included using recycled materials for labels or shorter labels as well as imprints to avoid printing the whole label again in case of mistakes or a new vintage year or changing legal requirements; getting rid of overpackaging; using recycled cardboard; reducing glass bottle weight; and the responsible sourcing of corks.

The interviewees seemed highly interested and dedicated to more sustainable environmental practices, and many felt personally involved in these issues. However, they remained rational and felt there were limits to their enthusiasm and willingness towards becoming more sustainable. They were reminded several times of the importance of the economic dimension that could present an obstacle to new investments or the lack of alternatives to replace current practices.

Finally, concerning socially sustainable practices at the distributor level, they were harder to identify and less numerous. One reason for this were the existing legal requirements in terms of employee compensation, safety, health and training. For employees, special benefits or bonuses linked to work performance were included in the salary package. Two important concepts: gender balance and inclusion were identified. To work on these concepts, one distributor had adapted its recruitment tool to increase diversity within the company.

For the community, distributors had a responsibility to educate and to help them when possible. For consumers, distributors have the duty to transmit the right messages and to be as transparent as possible.

For the supermarkets, reducing $\mathrm{CO}_{2}$ emissions and energy use were the main concerns. Conducting a carbon footprint audit allowed supermarkets to identify precisely which activities: processing, transport, storage, customers' journey and product implementation and which components: raw materials and packaging, were responsible for what level of carbon emissions. Once these had been identified, a global approach could be conducted both at the store level and at the plant level to reduce $\mathrm{CO}_{2}$ emissions.

Transport was responsible for the highest level of $\mathrm{CO}_{2}$ emissions. To tackle these emissions, supermarkets sought to improve the customers' journey by implementing charging stations for electric vehicles, often in partnership with automobile manufacturers. This allowed supermarkets to improve accessibility to green transport and to address the challenges of energy transition. However, transport was not only linked to the customers' journey but also to the supermarkets own transport chains by supporting sustainable last kilometer strategies with electric bike deliveries, and alternative transport means such as river and rail transport.

Concerning energy use, supermarkets identified a number of energy consuming activities such as refrigeration of shelves, lighting, air conditioning, computers and payment terminals. Actions had been taken to become more energy efficient and reduce energy costs through switching to natural refrigerants or implementing a LED lighting system. From a global building perspective, eco-designing buildings was a practice mentioned to support construction and renovation projects. Lastly, solar energy was mentioned as a sustainable practice and was currently under study for different sites in partnership with the Ministry of Economical and Solidarity Transition. 
Packaging was the other main issue for supermarkets. In terms of the customers' journey, supermarkets had stopped using single-use plastic bags: some did it as a voluntary practice while others waited for it to become a legal obligation. Reducing waste was achieved at source by eliminating unnecessary packaging and reducing it to a minimum through an improved eco-design for packages or packages made from certified materials. When this was not possible, the used packages need to be recyclable or compostable. To tackle this issue, supermarkets made specific instructions on packages for consumers to know how to recycle packages or implement local sorting and recycling lines.

Supermarkets had also implemented specific practices in the selection of their products and suppliers. Wherever possible, selecting wines and products from local suppliers was performed to reduce transport and the carbon footprint. Promoting eco-responsible products that were either organic $(\mathrm{AB})$, labeled under the HVE3 certification, or supporting alternative agricultural models such as agroecology was another. These could be achieved through partnerships with selected suppliers.

Biodiversity was mentioned only one time. At a store level, supermarkets could enhance biodiversity by using rooftops and dedicated space to experiment with permaculture or to install beehives.

In terms of global standards and certifications, ISO 50001 was mentioned by supermarkets as a means of energy management to be certified to an international standard.

In terms of socially sustainable practices, practices benefiting the local community and employees were identified. Supermarkets partnered with NGOs and associations to reduce food waste and poverty: their common actions included daily food donations.

Supermarkets also created partnerships with associations to integrate refugees and people with disabilities. One practice directly linked with wine was a partnership with wines from ESAT vineyards allowing the creation of new jobs for people with disabilities. As supermarkets also felt that they had a role to play in health and nutrition, to tackle this global issue, they often organized conferences and nutritional diagnosis.

Nevertheless, while supermarkets had implemented different practices directly linked to social and environmental sustainability, all of these actions were driven with their main $\mathrm{KPI}$ in mind: turnover per square meter.

For specialty wine stores, $\mathrm{CO}_{2}$ emissions were mainly linked with transport. However, most respondents felt that transporters were responsible for these emissions and that their impact was very limited. To reduce $\mathrm{CO}_{2}$ emissions, one identified practice was to group orders.

Concerning energy consumption, specialty wine stores required air conditioning, heating and/or refrigeration. Identifying sustainable practices was quite challenging, but specialty stores could reduce their energy consumption by heating or air conditioning only when necessary. They could also work with responsible electricity suppliers supporting green electricity.

Packaging and waste were an issue where specialty shops felt they could have a more positive impact. They could avoid using bags, and when they did, use paper or kraft bags that were more easily recycled than plastic. Specialty shops also mentioned reusing packaging received with the delivery of wine such as cardboard cartons or wooden boxes. In terms of recycling, cardboard, paper and pallets were recycled through the transporter or through a waste collection center. Corks, however, were not recycled.

In selecting their suppliers, respondents mentioned some practices such as supporting and selecting local wines from adjacent terroirs. Another identified practice was to work with certified wines: AB, HVE3 or biodynamic wines.

Socially sustainable practices were more challenging to identify. Practices benefitting local communities were mentioned only once, by participating in an initiative to give $1 \%$ of their turnover to an environmental fund distributing donations to NGOs and associations acting for environmental causes.

Practices benefitting employees included all legal benefits, as well as flexibility in terms of work schedule, discounts on products as well as a bonus system targeted on sales. 
Economically, specialty wine stores often found themselves in a difficult position: on one hand, they had to maintain prices to generate sufficient margins, but on the other hand, their prices had to be competitive (with the supermarkets) to avoid losing customers.

For the food service sector, transport was also the main issue in terms of reducing $\mathrm{CO}_{2}$ emissions. Interviewees mentioned that space constraints required more frequent truck deliveries. One interviewee had implemented a green last kilometer strategy by using electric vehicles for deliveries.

In terms of packaging and waste, while some did not undertake any kind of sorting or recycling, others sorted and recycled glass, cardboard and pallets for collection by transporters or dedicated bins managed by the municipality or at voluntary disposable points. For corks, some food service respondents collected them and recycled them for different purposes such as giving them away to a nonprofit organization for them to be transformed into insulating boards, slats, or for artistic purposes.

For organic waste, one interviewee recycled their waste through compost and a methane digester to generate green energy.

In the selection of products and suppliers, sustainability was not the first criterion. Food service actors highlighted taste and aroma, value for money, and consistency with the menu. However, even where it was not the first criterion, many still included certified wines in their offer such as organic (AB), HVE3 or biodynamic wines. Thus, supporting and offering certified products as well as working directly with producers and small winegrowers was identified as a sustainable practice.

Different sustainable practices that were not directly linked with wine were also identified. Food service actors focused on important issues for them that were affecting their core activity. These practices include reducing water consumption through improved shower and toilet systems and reprocessing cooking oils into biofuel through a certified service provider. Concerning biodiversity, one practice was identified: having a kitchen garden with herbs, vegetables and fruit trees.

At the food service level, it was more challenging to identify socially sustainable practices. Respondents mentioned partnerships with an ESAT to foster inclusion and employment for people with disabilities. This practice was supported by the government as it led to a tax deduction for clients using the service of this food service actor. International solidarity was also mentioned, implemented through solidarity dinners financing specific actions, including the training of foreign students, or making donations through the online booking system.

In terms of practices benefiting employees, most relied on existing legal obligations and had not put in place additional practices. Identified practices included bonuses linked to productivity, incentives for seasonal workers such as housing, laundering and meals, as well as specific training programs in cuisine for example.

To reduce their $\mathrm{CO}_{2}$ emissions, the interviewed online retailer mentioned several different practices. First, favoring shorter distribution chains or having an adapted last kilometer strategy using green transport such as bicycles. This respondent also mentioned participating in trade fairs, which allowed them to sell directly to end consumers and thus to limit transport costs.

In terms of energy consumption, as this retailer sold online through an e-commerce website, different suppliers were in charge of storage and transport. Thus, the online retailer felt that these service providers should take actions to reduce energy consumption.

For packaging and waste, it was difficult to analyze any practices other than the collection and reuse of pallets from transporters. However, this online retailer did consider sustainability when selecting wines and actively supported organic wines.

Finally, concerning socially sustainable practices, this online retailer had created a nonprofit organization aiming at enhancing the terroir. Through this association, wine grape growers had gained visibility and could communicate and share their best practices with others in terms of sustainability. 


\subsection{Implications}

\subsubsection{Environmentally Sustainable Practices}

Each actor of the WVC has different sustainability concerns and focused on different issues, depending on the activities they undertook in the value chain.

At the vineyard level, for wine grape growers, it was necessary to focus on the soil. Identified environmentally sustainable practices included protecting and improving the soil, reducing the use of phytosanitary products and using alternatives to these chemicals, as well as collecting and recycling effluents. A second focus was made on biodiversity with practices enhancing and protecting the fauna and flora. Another important focus for this actor was water management and reducing $\mathrm{CO}_{2}$ emissions.

At the winery level, the main focus was on electricity and water consumption as well as the use of inputs directly linked with wine processing methods. This actor also considered the sustainability of the packaging and dry materials used in the bottling process.

Vineyard and winery level activities were generally governed by the adoption of environmental management systems that both demonstrated and promoted their good practices to downstream customers.

As mentioned by Flint and Golicic (2009) [30], the distribution and retail channels sought to minimize transportation costs and reducing $\mathrm{CO}_{2}$ emissions. At the distribution level, this issue was tackled through practices optimizing short distribution chains and alternative forms of transport. Distributors also intervened in the upstream part of the chain to support wine producers through clearly identified practices such as an environmental charter. Distributors also had an impact at the office level by reducing and recycling wastes. For those distributors buying wine in bulk, they had a greater opportunity to act as they were involved in more activities and could implement practices linked with recyclable packaging and water management.

At the retail level, reducing $\mathrm{CO}_{2}$ emissions was the most challenging aspect. Identified practices included identifying and reducing emissions at each stage of their activity: processing, transport, storage, product implementation and the customers' journey and for all components: raw materials and packaging. Potentially, retailers could support green transport (electric and natural gas vehicles) for the customers' journey and in their last kilometer strategy.

Energy consumption was another issue for retailers as the sales area required refrigeration, lighting, air conditioning and heating. Various practices were identified to control and reduce energy consumption.

For packaging, the three R's (reduce, recycle and reuse) was extensively used to promote more sustainable practices.

The selection of products, through supporting eco-labeled, certified products and committed suppliers was one of the main practices illustrating the links between the different actors.

For actors in the WVC to be sustainable, retailers and businesses needed to work with local businesses that shared the same values [30]. In many instances, this had been achieved by supporting local wine producers and shorter production and distribution chains.

\subsubsection{Socially Sustainable Practices}

As identified by Forbes and da Silva (2020) [3], the people involved in the wine industry include employees, the local community, wider society, consumers and other stakeholders. This study clearly demonstrates the importance of employees and local communities as actors in the WVC.

According to Thach (2002) [33], socially sustainable practices benefitting employees are mainly linked with HR practices. For wine grape growers and wine producers, activities focused on occupational health and safety, well-being and working conditions, training, reward and remuneration, and employee's empowerment. Recruitment was a specific issue as wineries often faced a specific challenge in recruiting suitably qualified employees. 
For distributors, identified practices included reward and remuneration, inclusion and gender balance.

Retailers referred to existing legal obligations, but some voluntary practices included financial incentives, schedule flexibility, and training.

The Code Workbook (2012) [32] provided insights into the main issues concerning wine grape growers' and wine producers' issues with neighbors and the local community. Identified sustainable practices for wineries included understanding, respecting and communicating with the local community to tackle community issues such as noise, odors, chemicals and traffic.

The notion of the local community was broader when looking at other actors of the WVC and could include consumers or society. For distributors, identified practices included solidarity towards disadvantaged neighborhoods, communicating the right messages and being transparent with consumers in accordance with their responsibility.

For retailers, partnerships with NGOs and nonprofit organizations were extensively used to tackle issues such as food waste and poverty or inclusion.

\subsubsection{Economical Sustainability}

While the focus of this study was essentially on environmental and socially sustainable practices, sustainability relies on three pillars including the economic aspect. Throughout this study, at each level of the WVC, economic aspects were reinforced and outlined.

As the wine industry is currently operating with production surpluses [19] and Bordeaux has a market surplus of 600,000 hectoliters, the current situation for all the actors is tense. These actors are operating with products and equipment that are expensive, and the costs related to employees and labor are high, which makes it difficult to generate a profit. Moreover, costs linked to electricity and gas, oil, taxes and chemical inputs are continuously increasing.

Without profit, it is very challenging for actors in the WVC to make the necessary investments to comply with sustainable practices. Each of the different actors in the WVC outlined the importance of profitability before sustainability.

For wine grape growers and wine producers, the selling price of their bottle was a determinant for the investments they could make in terms of more sustainable technologies and packaging.

For distributors, the first objective was profitability, which meant implementing measures that were economically, environmentally and socially feasible.

For retailers, the main KPI was turnover per square meter and generating sufficient margins, thus all environmental and social practices were highly dependent on the end consumers' willingness to pay.

Moreover, the different actors insisted on the fact that each individual had a role to play in sustainability: producers, distributors, retailers and consumers should all accept some responsibility.

\section{Conclusions}

Sustainability has become a major concern for all food value chains to reduce the negative impact they induce on the environment and to reduce the negative impacts of climate change. Encouraging the adoption of more sustainable approaches and supporting alternative practices that are economically viable, environmentally friendly and socially responsible are ways of contributing to the SDGs.

Through this study, actors of the Bordeaux WVC have been studied to understand and identify socially and environmentally sustainable practices at each level of the chain. This study helps identify concrete sustainable practices both environmentally and socially.

The main objective was to capture the alignment of these actors in terms of practices. As practices are highly dependent on the activities operated by each actor, it was important to clearly identify the activities and the practices linked with these activities. It was 
then possible to identify whether or not there were common practices and any alignment between actors.

Based on this study, it can be concluded that all actors of the WVC have different practices that depend on the core activities for which they are responsible. However, some actors share common practices and there is some downstream pressure for market intermediaries to support sustainable practices at the wine grape grower and wine producer level. While WVC actors are more involved in environmental than socially sustainable practices, the regulatory framework shapes most socially sustainable practices, creating an alignment in terms of these specific practices.

\section{Limitations}

The first limitation to this study is linked to the fact that only the Bordeaux wine value chain was studied, hence limiting the generalization of the research findings. Furthermore, it is complex to assess all the sustainable practices, both environmental and social, at such a level. Thus, findings cannot be generalized to all WVC nor to all French WVC.

A second limitation of this study was that the consumption aspect of the WVC was not studied even though consumers are an important actor of the WVC. Consumers store and consume wine, but were not included as an actor in this study, hence we were unable to take into consideration many practices such as the treatment of the bottles (reuse, recycling, landfilling, etc.), waste handling of packaging (cardboard boxes, corks, etc.) and the negative impact the disposal of these items may have on the environment [25].

A third limit is the fact that the information used for this study was directly provided by the different actors of the WVC and may thus be considered subjective. This study measures the intentions of the different actors of the WVC but does not study the impact of the different sustainable practices that they have implemented.

Future studies on this topic could be conducted in other wine value chains and in other regions to determine if the findings can be generalized to other value chains. They could also include quantitative analysis to verify the reliability of the presented results. Moreover, future studies should study the consumption aspect.

It would also be interesting to conduct this type of study from a Life Cycle Sustainability Assessment (LCSA) perspective that would focus on the product directly, meaning focusing on wine instead of focusing on the different actors of the wine value chain. Taking into account the real environmental impact associated with wine production, marketing and consumption could help promote awareness among value chain actors and go from subjective intentions to a measure of the objective impacts of practices on sustainability.

Author Contributions: Conceptualization, methodology, formal analysis, investigation, writingoriginal draft preparation and writing — review and editing, C.T.; writing-review and editing and supervision, P.J.B. All authors have read and agreed to the published version of the manuscript.

Funding: This research received no external funding.

Institutional Review Board Statement: Not applicable.

Informed Consent Statement: Informed consent was obtained from all subjects involved in the study.

Conflicts of Interest: The authors declare no conflict of interest.

\section{References}

1. Bongaarts, J. The State of Food and Agriculture. In Food \& Agriculture Organization of the United Nations-Population and Development Review; FAO: Rome, Italy, 2017. [CrossRef]

2. Shnayder, L.; Van Rijnsoever, F.J.; Hekkert, M.P. Putting your money where your mouth is: Why sustainability reporting based on the triple bottom line can be misleading. PLOS ONE 2015, 10, e0119036. [CrossRef]

3. Forbes, S.L.; Da Silva, T.A. Analysis of environmental management systems in New Zealand wineries. Int. J. Wine Bus. Res. 2012, 24, 98-114. [CrossRef]

4. Merli, R.; Preziosi, M.; Acampora, A. Sustainability experiences in the wine sector: Toward the development of an international indicators system. J. Clean. Prod. 2018, 172, 3791-3805. [CrossRef] 
5. OIV. Resolution OIV-CST 518-2016. OIV General Principles of Sustainable Vitiviniculture-Environmental, Social, Economic and Cultural Aspects. 2016. Available online: http://www.oiv.int/public/medias/5766/oiv-cst-518-2016-en.pdf. (accessed on 23 October 2020).

6. Silverman, M.; Marshall, R.S.; Cordano, M. The greening of the California wine industry: Implications for regulators and industry associations. J. Wine Res. 2005, 16, 151-169. [CrossRef]

7. Marshall, R.S.; Cordano, M.; Silverman, M. Exploring individual and institutional drivers of proactive environmentalism in the US Wine industry. Bus. Strategy Environ. 2005, 14, 92-109. [CrossRef]

8. Gabzdylova, B.; Raffensperger, J.F.; Castka, P. Sustainability in the New Zealand wine industry: Drivers, stakeholders and practices. J. Clean. Prod. 2009, 17, 992-998. [CrossRef]

9. Dodds, R.; Graci, S.; Ko, S.; Walker, L. What drives environmental sustainability in the New Zealand wine industry? An examination of driving factors and practices. Int. J. Wine Bus. Res. 2013, 25, 164-184. [CrossRef]

10. Santini, C.; Cavicchi, C.; Casini, L. Sustainability in the wine industry: Key questions and research trends. Agric. Food Econ. 2013, 1,1-14. [CrossRef]

11. Szolnoki, G. A cross-national comparison of sustainability in the wine industry. J. Clean. Prod. 2013, 53, 243-251. [CrossRef]

12. Pomarici, E.; Vecchio, R. Will sustainability shape the future wine market? Wine Econ. Policy 2019, 8, 1-4. [CrossRef]

13. Gilinsky, A.; Newton, S.K.; Vega, R.F. Sustainability in the Global Wine Industry: Concepts and Cases. Agric. Agric. Sci. Procedia 2016, 8, 37-49. [CrossRef]

14. Spielmann, N. Larger and better: Examining how winery size and foreign investments interact with sustainability attitudes and practices. Int. J. Wine Bus. Res. 2017, 29, 178-194. [CrossRef]

15. Soosay, C.; Fearne, A.; Dent, B. Sustainable value chain analysis-A case study of Oxford Landing from vine to dine. Supply Chain Manag. 2012, 17, 68-77. [CrossRef]

16. Ponstein, H.J.; Ghinoi, S.; Steiner, B. How to increase sustainability in the Finnish wine supply chain? Insights from a country of origin based greenhouse gas emissions analysis. J. Clean. Prod. 2019, 226, 768-780. [CrossRef]

17. Baiano, A. An Overview on Sustainability in the Wine Production Chain. Beverages 2021, 7, 15. [CrossRef]

18. Le Comité National de Interprofessions des Vins à Appellation D'origine et à Indication Géographique. 2018. Available online: https: / / www.intervin.fr/ (accessed on 19 October 2020).

19. OIV. 2019. Available online: http:/ / www.oiv.int/public/medias/6679/en-oiv-state-of-the-vitiviniculture-world-market-2019 .pdf. (accessed on 23 October 2020).

20. Conseil Interprofessionnel du Vin de Bordeaux. 2019. DOSSIER DE PRESSE BILAN STRATEGIE 2018-2019. 2019. Available online: DP_CIVB_général_2019_BAT_Bassedéf.pdf (accessed on 22 October 2020).

21. Elkington, J. Cannibals with forks: The Triple Bottom Line of 21st Century Business; Oxford University Press: Capstone, AB, Canada, 1999.

22. Smith, M. Business Sustainability and the Triple Bottom Line: Considering the Interrelationships of People, Profit and Planet. In Learner-Centered Teaching Activities for Environmental and Sustainability Studies; Byrne, L., Ed.; Springer: Cham, Switzerland, 2016.

23. Ouvrard, S.; Jasimuddin, S.M.; Spiga, A. Does Sustainability Push to Reshape Business Models? Evidence from the European Wine Industry. Sustainability 2020, 12, 2561. [CrossRef]

24. Pullman, M.E.; Maloni, M.J.; Dillard, J. Sustainability Practices in Food Supply Chains: How is Wine Different? J. Wine Res. 2010, 21, 35-56. [CrossRef]

25. Goncharuk, A.G. Wine Value Chains: Challenges and Prospects. J. Appl. Manag. Investig. 2017, 6, 11-27.

26. Meissenheimer, J.; Karaan, A.S.M.; Vink, N. Sources of Transaction Costs in the South African Wine Supply Chain: Implications for Enhancing Chain Competitiveness; Department of Agricultural Economics, University of Stellenbosch: Stellenbosch, South Africa, 2001.

27. Pesme, J.O.; Bélis-Bergouignan, M.C. Strategic operations and concentration in the Bordeaux-Aquitaine wine sector. Int. J. Wine Bus. Res. 2010, 22, 308-324.

28. Ohmart, C. Innovative outreach increases adoption of sustainable winegrowing practices in Lodi region. Calif. Agric. 2008, 62, 142-147. [CrossRef]

29. Brunori, G.; Galli, F.; Barjolle, D.; Van Broekhuizen, R.; Colombo, L.; Giampietro, M.; Kirwan, J.; Lang, T.; Mathijs, E.; Maye, D.; et al. Are Local Food Chains More Sustainable than Global Food Chains? Considerations for Assessment. Sustainability 2016, 8, 449. [CrossRef]

30. Flint, D.J.; Golicic, S.L. Searching for competitive advantage through sustainability: A qualitative study in the New Zealand wine industry. Int. J. Phys. Distrib. Logist. Manag. 2009, 39, 841-860. [CrossRef]

31. Barbosa, F.S.; Scavarda, A.J.; Sellitto, M.A.; Marques, D.I.L. Sustainability in the winemaking industry: An analysis of Southern Brazilian companies based on a literature review. J. Clean. Prod. 2018, 192, 80-87. [CrossRef]

32. California Sustainable Winegrowing Alliance; California Association of Winegrape Growers. California Code of Sustainable Winegrowing Workbook; California Sustainable Winegrowing Alliance, Wine Institute, and California Association of Winegrape Growers: San Francisco, CA, USA, 2012.

33. Thach, L. Social Sustainability in the Wine Community; 2002; Available online: https://www.winebusiness.com/wbm/?go= getArticle\&dataId=17442 (accessed on 26 October 2020).

34. Flores, S.S. What is sustainability in the wine world? A cross-country analysis of wine sustainability frameworks. J. Clean. Prod. 2018, 172, 2301-2312. [CrossRef] 
35. Firouzeh, T.; Jay, D.; Grant, M. Profit, planet and people in supply chain: Grand challenges and future opportunities. In Proceedings of the 25th European Conference on Information Systems, ECIS, Guimarães, Portugal, 5-10 June 2017; pp. 1299-1313.

36. Moscarola, J. Méthodes d'enquête et d'analyse de données. Création Connaiss. Manag. 2015, January $2015,1-17$.

37. Palinkas, L.A.; Horwitz, S.; Green, C.; Wisdom, J.; Duan, N.; Hoagwood, K. Purposeful Sampling for Qualitative Data Collection and Analysis in Mixed Method Implementation Research. Adm. Policy Ment. Health Ment. Heal. Serv. Res. 2013, 42, 533-544. [CrossRef] [PubMed]

38. Elo, S.; Kyngäs, H. The qualitative content analysis process. J. Adv. Nurs. 2008, 62, 107-115. [CrossRef]

39. Moscarola, J.; Jenkins, M. Content and Lexical Analysis: A Qualitative Practical Application. Management 1998, $070498,1-36$. [CrossRef] 